\title{
Incorporating Pitzer equations in a new thermodynamic model for the prediction of acid gases solubility in aqueous alkanolamine solutions
}

\section{Citation for published version (APA):}

Alhseinat, E., Mota Martinez, M., Peters, C. J., \& Banat, F. (2014). Incorporating Pitzer equations in a new thermodynamic model for the prediction of acid gases solubility in aqueous alkanolamine solutions. Journal of Natural Gas Science and Engineering, 20, 241-249. https://doi.org/10.1016/j.jngse.2014.07.003

DOI:

10.1016/j.jngse.2014.07.003

Document status and date:

Published: 01/01/2014

\section{Document Version:}

Publisher's PDF, also known as Version of Record (includes final page, issue and volume numbers)

\section{Please check the document version of this publication:}

- A submitted manuscript is the version of the article upon submission and before peer-review. There can be important differences between the submitted version and the official published version of record. People interested in the research are advised to contact the author for the final version of the publication, or visit the DOI to the publisher's website.

- The final author version and the galley proof are versions of the publication after peer review.

- The final published version features the final layout of the paper including the volume, issue and page numbers.

Link to publication

\footnotetext{
General rights

- You may freely distribute the URL identifying the publication in the public portal. follow below link for the End User Agreement:

www.tue.nl/taverne

\section{Take down policy}

If you believe that this document breaches copyright please contact us at:

openaccess@tue.nl

providing details and we will investigate your claim.
}

Copyright and moral rights for the publications made accessible in the public portal are retained by the authors and/or other copyright owners and it is a condition of accessing publications that users recognise and abide by the legal requirements associated with these rights.

- Users may download and print one copy of any publication from the public portal for the purpose of private study or research.

- You may not further distribute the material or use it for any profit-making activity or commercial gain

If the publication is distributed under the terms of Article $25 \mathrm{fa}$ of the Dutch Copyright Act, indicated by the "Taverne" license above, please 


\title{
Incorporating Pitzer equations in a new thermodynamic model for the prediction of acid gases solubility in aqueous alkanolamine solutions
}

\author{
Emad Alhseinat, Maria Mota-Martinez, Cornelis Peters, Fawzi Banat* \\ Department of Chemical Engineering, The Petroleum Institute, PO Box 2533, Abu Dhabi, United Arab Emirates
}

\section{A R T I C L E I N F O}

\section{Article history:}

Received 18 March 2014

Received in revised form

2 July 2014

Accepted 3 July 2014

Available online 26 July 2014

\section{Keywords:}

Solubility

MDEA

Pitzer

Acid gases

Thermodynamic

Gibbs

\begin{abstract}
A B S T R A C T
In gas sweetening, acid gases such as $\mathrm{CO}_{2}$ and/or $\mathrm{H}_{2} \mathrm{~S}$ are usually removed by "chemical" absorption through aqueous amine solutions such as N-Methyldiethanolamine (MDEA) solution. Reliable prediction of equilibrium properties (vapor-liquid equilibrium and species distribution) is needed for a rigorous design of such absorption processes. Information on energy requirements can also be obtained from a reliable vapor-liquid equilibrium thermodynamic model. The currently used methods for correlating/ predicting the simultaneous solubility of $\mathrm{H}_{2} \mathrm{~S}$ and $\mathrm{CO}_{2}$ in aqueous MDEA solutions require accurate experimental solubility data of single and mixed gases which, in general, confine their applicability in the experimental region. The purpose of this paper is to develop a new theoretical thermodynamic model based on incorporating thermodynamic relationships that correlates the equilibrium and solubility constants to the Gibbs free energy of reaction, leading to an enhanced predictive capability of the model. In this work the Pitzer model is used to account for activity and specific ion interactive forces. This will allow taking into account the effect of the presence of all cations and anions such as thermally stable salts, dissolved organic species and amine degradation products that are usually encountered in absorption units. The suggested model has been verified through comparison with literature data for $\mathrm{CO}_{2}$ and $\mathrm{H}_{2} \mathrm{~S}$ absorption. The presented model can be a very powerful tool that could be of significant importance in the design of amine absorption processes as well as in simulations of the operating variables for optimization of gas sweetening systems.
\end{abstract}

(C) 2014 Elsevier B.V. All rights reserved.

\section{Introduction}

Acid gases such as hydrogen sulfide and carbon dioxide are major impurities in natural, refinery, and synthesis gases. Chemical absorption by aqueous solutions of amines such as N-Methyldiethanolamine (MDEA) solution is one of the most effective industrial methods for the removal of these acid gases from gaseous effluents (Speyer et al., 2012, 2009). Availability of accurate acid gas solubilities in the solvent is essential for any modeling of absorption processes. A number of models such as Kent-Eisenberg (KE), Modified Kent-Eisenberg (M-KE), Deshmukh and Mather model, Electrolyte-NRTL, Extended Debye-Hückel (E-DH), Pitzer and $\mathrm{Li}-$ Mather models were proposed to correlate solubility data (Benamor and Aroussi, 2013). Kent and Eisenberg (1976) modeled the solubility of acid gases and their mixtures in MEA and DEA aqueous solutions. In this model equilibrium constants of

\footnotetext{
* Corresponding author. Tel.: +971 2 6075099; fax: +97126075200

E-mail addresses: fbanat@pi.ac.ae, banatf@just.edu.jo (F. Banat).
}

carbamate formation and protonation of the amines have been considered to be only temperature-dependent. The KE model is an empirical model and, therefore, it cannot properly predict the solubility of acid gases in aqueous amine solutions in a wide range of temperature, pressure and amine concentrations. The NRTL model (Chen and Evans, 1986) and the model of Deshmukh and Mather (Deshmukh and Mather, 1981) are based on sound thermodynamic principles. Non-idealities of the solution are taken into consideration by considering long and short range interactions between the different species present in the solution. The NRTL model used a combination of Debye-Hückel theory and the electrolyte-NRTL equation to calculate the activity coefficients. The Deshmukh and Mather model is much simpler to handle than the NRTL model. It employs the Guggenheim equation to represent activity coefficients. The Kent and Eisenberg model is the simplest among all mentioned models. The non-idealities present in the system are lumped together and represented by constant values (Benamor and Aroussi, 2013). Unfortunately, there are still significant limitations in models currently in use to predict acid gas solubilities in amine solutions. These limitations are mainly caused by the use of 
empirical approaches, in which crude assumptions have been introduced. In the best scenario these models are mainly useful to correlate experimental data.

To enhance the reliability of solubility predictions of acid gases in aqueous amine solutions, the following can be done: Firstly, implementation of sound thermodynamic relations to account for the equilibrium constants rather than just correlating the experimental data at specific conditions. Application of thermodynamically reliable equations will account for the effect of temperature and pressure on equilibrium constants and solubilities. Secondly, the activity coefficients of the species present in the aqueous phase and the fugacity coefficients of the species present in the vapor phase must be considered. The Debye-Hückel and the extended Debye-Hückel theory are the basis of a number of successful semi-empirical equations for a variety of thermodynamic properties (Loehe and Donohue, 1997). Pitzer and coworkers established very widely applicable equations for calculating the activity coefficients of individual species in aqueous media at high concentrations. In his publications (Pitzer and Mayorga, 1973; Pitzer, 1991) the origin of these equations and their application are discussed in some detail. To consider the deviation of real gas phase behavior from the ideal gas state, the Virial (George Hayden and O'Connell, 1975), PR (Peng and Robinson, 1976) or SRK (Soave, 1972) equations of state (EOS) can be used to calculate the fugacity-coefficients of the components in the gas phase.

In this work, a new theoretical thermodynamic model will be developed based on incorporating theoretical thermodynamic relationships that correlates the equilibrium and solubility constants to the Gibbs free energy of reactions. For the first time, the effect of temperature and pressure will be incorporated through fundamental thermodynamic equations. The Pitzer model and the PR EOS will be used to account for activity coefficients and fugacity coefficients, respectively. The application of the Pitzer model will allow considering the effect of ion-specific interactive forces that results from the presence of heat stable salts, dissolved organic and amine degradation products that are usually encountered in absorption units.

\section{Theory and framework of our model}

In this section the N-Methyldiethanolamine (MDEA), $\mathrm{H}_{2} \mathrm{~S}$ and $\mathrm{CO}_{2}$ system has been used as an example to demonstrate the model framework. The following assumptions have been made: (i) the volatility of the amine has been neglected; (ii) in the liquid phase, hydrogen sulphide and carbon dioxide are dissolved in the liquid phase not only in neutral, but also in non-volatile ionic form. The following reversible chemical reactions (chemical equilibrium) are taken into account: (i) the auto-protolyses of water (R1), the formations of hydrosulfide (bisulfide) and sulfide (R2, R3), (ii) the formation and dissociation of bicarbonate (R4 and R5), (iii) the protonation of MDEA (R6).

$\mathrm{H}_{2} \mathrm{O} \underset{K_{\mathrm{R} 1}}{\Leftrightarrow} \mathrm{H}^{+}+\mathrm{OH}^{-}$

$\mathrm{H}_{2} \mathrm{~S} \underset{K_{\mathrm{R} 2}}{\Leftrightarrow} \mathrm{HS}^{-}+\mathrm{H}^{+}$

$\mathrm{HS}^{-} \underset{K_{\mathrm{R} 3}}{\Leftrightarrow} \mathrm{H}^{+}+\mathrm{S}^{2-}$

$\mathrm{CO}_{2}+\mathrm{H}_{2} \mathrm{O} \underset{K_{\mathrm{R} 4}}{\Leftrightarrow} \mathrm{H}^{+}+\mathrm{HCO}_{3}^{-}$
$\mathrm{HCO}_{3}^{-} \underset{K_{\mathrm{R} 5}}{\Leftrightarrow} \mathrm{H}^{+}+\mathrm{CO}_{3}^{2-}$

$\mathrm{MDEAH}^{+} \underset{K_{\mathrm{R}}}{\Leftrightarrow} \mathrm{H}^{+}+$MDEA

The chemical reaction equilibrium constants $\left(K_{\mathrm{R} 1}-K_{\mathrm{R} 6}\right)$ will be calculated from the Gibbs free energy of reaction. Then the effect of temperature and pressure will be taken into account as will be explained in detail later.

The condition for chemical equilibrium for a chemical reaction $\mathrm{R}$ $(=1, \ldots, 6)$ is:

$K_{\mathrm{R}}(T, P)=\prod_{i} a_{i}^{V_{i, \mathrm{R}}}$

where $K_{\mathrm{R}}(T, P)$ is the chemical reaction equilibrium constant for reaction $\mathrm{R}, a_{i}$ is the thermodynamic activity of species $i$ in the liquid phase, and $\nu_{i, \mathrm{R}}$ is the stoichiometric coefficient of species $i$ in reaction R.

Applying mass conservation equations on carbon dioxide, hydrogen sulfide, MDEA, and water result in:

$\bar{m}_{\mathrm{CO}_{2}}=m_{\mathrm{CO}_{2}}+m_{\mathrm{HCO}_{3}^{-}}+m_{\mathrm{CO}_{3}^{2-}}$

$\bar{m}_{\mathrm{H}_{2} \mathrm{~S}}=m_{\mathrm{H}_{2} \mathrm{~S}}+m_{\mathrm{HS}^{-}}+m_{\mathrm{S}^{2-}}$

$\bar{m}_{\mathrm{MDEA}}=m_{\mathrm{MDEA}}+m_{\mathrm{MDEAH}^{+}}$

$\bar{m}_{\mathrm{w}}=m_{\mathrm{w}}+m_{\mathrm{HCO}_{3}^{-}}+m_{\mathrm{CO}_{3}^{2-}}+m_{\mathrm{OH}^{-}}$

The condition for liquid-phase electro-neutrality is:

$m_{\mathrm{MDEAH}^{+}}+m_{\mathrm{H}^{+}}=m_{\mathrm{OH}^{-}}+m_{\mathrm{HS}^{-}}+2 m_{\mathrm{S}^{2-}}+m_{\mathrm{HCO}_{3}^{-}}+2 m_{\mathrm{CO}_{3}^{2-}}$

where $\bar{m}_{i}$ is the amount of substance $i$ in the liquid feed. The speciation, i.e., the "true" composition of the liquid phase (the amount of substance $m_{i}$ of all species present) is obtained by solving this set of equations for a given temperature, pressure and stoichiometric amounts of substances $\bar{m}_{i}$ of the components $\mathrm{H}_{2} \mathrm{O}$, MDEA, $\mathrm{CO}_{2}$ and $\mathrm{H}_{2} \mathrm{~S}$. This speciation is required to determine the composition of the vapor phase.

The activity of species $i$ is normalized according to Henry's law on the molality scale:

$a_{i}=m_{i} \gamma_{i}$

where $m_{i}$ and $\gamma_{i}$ are the molality and the molality-based activity coefficient of solute species $i$. The activity coefficients of all species are calculated with a modification of Pitzer's equation for the excess Gibbs energy of aqueous electrolyte solutions as will be discussed in more detail later in this paper.

For the vapor phase, the model applies the extended Henry's law on the molality scale to describe the partial pressure of $\mathrm{H}_{2} \mathrm{~S}$ and $\mathrm{CO}_{2}$ (i.e., the product of the total pressure $\mathrm{P}$ and vapor phase mole fractions $y_{\mathrm{H}_{2} \mathrm{~S}}$ and $y_{\mathrm{CO}_{2}}$ ) above the aqueous solution and the extended Raoult's law for water.

$k_{\mathrm{H}, \mathrm{H}_{2} \mathrm{~S}} \exp \left[\frac{v_{\mathrm{H}_{2} \mathrm{~S}}^{\infty}\left(P-P_{w}^{S}\right)}{R_{g} T}\right] a_{\mathrm{H}_{2} \mathrm{~S}}=y_{\mathrm{H}_{2} \mathrm{~S}} P \varphi_{\mathrm{H}_{2} \mathrm{~S}}$ 
$k_{\mathrm{H}, \mathrm{CO}_{2}} \exp \left[\frac{v_{\mathrm{CO}_{2}}^{\infty}\left(P-P{ }_{w}^{s}\right)}{R_{\mathrm{g}} T}\right] a_{\mathrm{CO}_{2}}=y_{\mathrm{CO}_{2}} P \varphi_{\mathrm{CO}_{2}}$

$P_{w}^{s} \varphi_{w}^{s} \exp \left[\frac{v_{w}\left(P-P_{w}^{s}\right)}{R_{g} T}\right] a_{w}=y_{w} P \varphi_{w}$

where $k_{H, i}$ is Henry's constant of species $i$ in water at temperature $T$, $R_{g}$ is the universal gas constant, and $P_{w}^{s}$ is the vapor pressure of water. $v_{w}$ and $v_{i}^{\infty}$ are the molar volume of liquid water and the partial molar volume of $i$ at infinite dilution in water, respectively. $\varphi_{i}$ and $\varphi_{w}$ are the fugacity coefficient of component $i$ and water, respectively, in the gaseous mixture that coexists with the liquid. $\varphi_{w}^{s}$ is the fugacity coefficient of water in its saturation state, and $a_{i}$ is the activity of species $i$ in the liquid state.

\section{Solubility prediction}

A more theoretical approach for predicting the solubility of the dissolved species in amine aqueous solution could be established based on a fundamental and unified methodology through incorporating the ion-activities and principles of thermodynamics including Gibbs free energies. In Eq. (1), the ions constituting the soluble component $\left(Y_{c} Z_{a}\right)$ are represented by " $Y$ " and " $Z$ ", and " $c$ " and " $a$ " are respectively the number of cations and anions in $1 \mathrm{~mol}$ of electrolyte, $e+$ and $e-$ are the valences for cation and anion, respectively.

$$
\begin{aligned}
& Y_{c} Z_{a} \overleftrightarrow{K_{\mathrm{R}}} c Y^{e+}+a Z^{e-} \\
& -R_{g} T \ln \left(K_{\mathrm{R}}\right)=\Delta_{\text {reac }} G^{\varphi} \\
& \Delta_{\text {reac }} G^{\varphi}=\left\{\sum \Delta_{f} G^{\varphi}\right\}_{\text {products }}-\left\{\sum \Delta_{f} G^{\varphi}\right\}_{\text {reactants }}
\end{aligned}
$$

The thermodynamic equilibrium constant, $K_{\mathrm{R}}$, is related to the Gibbs free energy of reaction $\left(\Delta_{\text {reac }} G^{\varphi}\right)$ according to Eq. (12) and related to the standard Gibbs free energies of formation $\left(\Delta_{f} G^{\varphi}\right)$ according to Eq. (13). Thermodynamic principles and relationships can be used to incorporate the effect of temperature and process pressure on the equilibrium constants as will be discussed here below.

\subsection{Effect of temperature}

The equilibrium product, $K_{\mathrm{R}}\left(T, P_{o}\right)$ at temperature $T$ and reference pressure $P_{o}$ ( 1 bar) can be calculated either from the Gibbs free energy change of reaction using Eq. (14) as described in Sheikholeslami (2004, 2005) and Alhseinat and Sheikholeslami (2012) or by using Eqs. (15)-(18) as described by Monnin (1999). Assuming the heat capacity is constant over the investigated temperature range then $K_{\mathrm{R}}\left(T, P_{0}\right)$ is given by:

$-R_{g} T \ln \left(K_{\mathrm{R}}\right)=\Delta_{r} G^{T}=\frac{T}{298.15} \Delta_{r} G^{298}+\Delta_{r} H^{298}\left(1-\frac{T}{298.15}\right)$

$\ln K_{\mathrm{R}}\left(T, P_{o}\right)=A+B \ln T+\frac{C}{T}$

With

$A=\frac{\Delta_{r} S^{o}}{R_{g}}-\frac{\Delta_{r} C_{p}^{o}}{R_{g}}\left[1+\ln T_{o}\right]$
$B=\frac{\Delta_{r} C_{p}^{o}}{R_{g}}$

$C=-\frac{\Delta_{r} H^{o}}{R_{g}}+\frac{T_{o} \Delta_{r} C_{p}^{o}}{R_{g}}$

where $\Delta_{r} S^{o}, \Delta_{r} H^{o}$ and $\Delta_{r} C_{p}^{o}$ respectively refer to standard entropy, enthalpy and heat capacity changes of the reaction. $T_{0}$ the reference temperature (298.15) (Monnin, 1999). Table 1 gives the thermodynamic standard properties for all species involved in R1-R6, and Table 2 gives the calculated change in thermodynamic properties for reactions $\mathrm{R} 1-\mathrm{R} 6$.

\subsection{Effect of pressure}

Effect of pressure on equilibrium can be calculated by integrating the following Eqs. (19) and (20) according to Alhseinat and Sheikholeslami (2012),

$\left(\frac{\partial \ln K_{\mathrm{R}}(T, P)}{\partial P}\right)_{r}=\frac{-\Delta V_{r}^{o}(T, P)}{R_{g} T}$

and

$\left(\frac{\partial \Delta V_{r}^{0}(T, P)}{\partial P}\right)_{T}=-\Delta K_{r}^{0}(T, P)$

where $\Delta V_{r}^{0}$ and $\Delta K_{r}^{0}$ stand for the standard volume and compressibility changes of the reaction (Alhseinat and Sheikholeslami, 2012).

The integration of Eqs. (19) and (20) leads to the following expression (Alhseinat and Sheikholeslami, 2012; Monnin, 1999; Rushdi et al., 2000).

$\ln K_{\mathrm{R}}(T, P)=\ln K_{\mathrm{R}}\left(T, P_{0}\right)-\frac{\Delta \overline{V_{r}^{0}}}{R_{g} T}\left(P-P_{o}\right)+\frac{\Delta \overline{K_{r}^{0}}}{2 R_{g}}\left(P-P_{o}\right)^{2}$

where $\Delta \overline{V_{r}^{0}}$ is the standard molal volume change of the reaction and $\Delta \overline{K_{r}^{0}}$ is its standard molal compressibility change. The effect of $\Delta \overline{K_{r}^{o}}$ can be neglected at moderate pressures range.

\subsection{Activity coefficients models}

Activity coefficients of electrolytes dissolved in aqueous solutions are a special subject of study in the electrochemical literature (van der Stegen et al., 1999). There are several semi-empirical models in the literature that can be used to predict the activity coefficients of electrolytes dissolved in aqueous solution, most of them were discussed in Anderko et al. (2002). The activity coefficients are necessary for the calculation of the electrochemical potential, which is a very important parameter in determining the thermodynamic equilibrium (van der Stegen et al., 1999). Thus, reliable prediction of the activity coefficients is essential to achieve reliable predictions of the solubility of acid gases in aqueous amine solutions.

The Poisson-Boltzmann equation and the Debye-Hückel theory are the basis of a number of successful semi-empirical equations for a variety of thermodynamic properties (Loehe and Donohue, 1997). The more popular of these equations are discussed in references Loehe and Donohue (1997) and Anderko et al. (2002). Perhaps the most widely applied of these equations are those developed by Pitzer and coworkers since 1973 (Loehe and Donohue, 1997). Pitzer (Pitzer and Mayorga, 1973; Pitzer, 1975, 1991; Pitzer and Silvester, 1978; Pitzer and Kim, 1974) discusses the origin of these equations and their application in some detail. 
Table 1

The thermodynamic standard properties for all species involves in R1-R6 at $298.15 \mathrm{~K}$ and 1 bar.

\begin{tabular}{|c|c|c|c|c|c|c|}
\hline & $\Delta_{f} G^{o}(\mathrm{~kJ} / \mathrm{mol})$ & $S^{o}(\mathrm{~J} / \mathrm{mol} \mathrm{K})$ & $\Delta_{f} H^{o}(\mathrm{~kJ} / \mathrm{mol})$ & $C_{p}^{o}(\mathrm{~J} / \mathrm{mol} \mathrm{K})$ & $\overline{V^{0}}\left(\mathrm{~cm}^{3} / \mathrm{mol}\right)$ & $\overline{K^{0}}\left(\mathrm{~cm}^{3} / \mathrm{MPa} \mathrm{mol}\right)$ \\
\hline $\mathrm{H}_{2} \mathrm{O}$ & $\begin{array}{l}\text {-237.13 (Wagman et al., } \\
\text { 1982) }\end{array}$ & $\begin{array}{l}69.91 \text { (Wagman et al., } \\
\text { 1982) }\end{array}$ & $\begin{array}{l}\text {-285.83 (Wagman } \\
\text { et al., 1982) }\end{array}$ & $\begin{array}{l}75.291 \text { (Wagman et al., } \\
\text { 1982) }\end{array}$ & $\begin{array}{l}\text { 18.068 (Barbero et al., } \\
1982 \text { ) }\end{array}$ & \\
\hline MDEA & $\begin{array}{l}\text {-169.00 (Zhang and Chen, } \\
\text { 2010) }\end{array}$ & - & $\begin{array}{l}\text {-380.00 (Zhang and } \\
\text { Chen, 2010) }\end{array}$ & $\begin{array}{l}380.90 \text { (Zhang et al., } \\
2002 \text { ) }\end{array}$ & $\begin{array}{l}109.50 \text { (Zhang et al., } \\
\text { 2002) }\end{array}$ & $\begin{array}{l}\text {-0.0008 (Zhang et al., } \\
\text { 2002) }\end{array}$ \\
\hline $\mathrm{MDEA}^{+}$ & $\begin{array}{l}\text {-217.800 (Zhang and Chen, } \\
\text { 2010) }\end{array}$ & - & $\begin{array}{l}\text {-512.22 (Zhang and } \\
\text { Chen, 2010) }\end{array}$ & $\begin{array}{l}198.80 \text { (Zhang et al., } \\
\text { 2002) }\end{array}$ & $\begin{array}{l}123.32 \text { (Zhang et al., } \\
\text { 2002) }\end{array}$ & $\begin{array}{l}\text {-0.00087 (Zhang et al., } \\
\text { 2002) }\end{array}$ \\
\hline $\mathrm{H}_{2} \mathrm{~S}$ & $\begin{array}{l}\text {-27.830 (Wagman et al., } \\
\text { 1982) }\end{array}$ & $\begin{array}{l}121.0 \text { (Wagman et al., } \\
\text { 1982) }\end{array}$ & $\begin{array}{l}-39.700 \text { (Wagman } \\
\text { et al., 1982) }\end{array}$ & $\begin{array}{l}178.50 \text { (Barbero et al., } \\
1982 \text { ) }\end{array}$ & $\begin{array}{l}39.920 \text { (Barbero et al., } \\
1982 \text { ) }\end{array}$ & - \\
\hline $\mathrm{HS}^{-}$ & $\begin{array}{l}12.080 \text { (Wagman et al., } \\
1982 \text { ) }\end{array}$ & $\begin{array}{l}62.80 \text { (Wagman et al., } \\
1982 \text { ) }\end{array}$ & $\begin{array}{l}-17.600 \text { (Wagman } \\
\text { et al., 1982) }\end{array}$ & $\begin{array}{l}\text {-92.000 (Barbero et al., } \\
\text { 1982) }\end{array}$ & $\begin{array}{l}20.800 \text { (Barbero et al., } \\
1982 \text { ) }\end{array}$ & - \\
\hline$S^{2-}$ & $\begin{array}{l}85.800 \text { (Wagman et al., } \\
1982 \text { ) }\end{array}$ & $\begin{array}{l}-14.60 \text { (Wagman et al., } \\
1982 \text { ) }\end{array}$ & $\begin{array}{l}33.100 \text { (Wagman et al., } \\
1982 \text { ) }\end{array}$ & - & - & - \\
\hline $\mathrm{CO}_{2}$ & $\begin{array}{l}\text {-394.37 (Wagman et al., } \\
\text { 1982) }\end{array}$ & $\begin{array}{l}\text { 117.6 (Wagman et al., } \\
\text { 1982) }\end{array}$ & $\begin{array}{l}\text {-393.51 (Wagman } \\
\text { et al., 1982) }\end{array}$ & - & - & - \\
\hline $\mathrm{HCO}_{3}^{-}$ & $\begin{array}{l}\text {-586.77 (Wagman et al., } \\
\text { 1982) }\end{array}$ & $\begin{array}{l}91.200 \text { (Wagman et al., } \\
1982 \text { ) }\end{array}$ & $\begin{array}{l}\text {-691.99 (Wagman } \\
\text { et al., 1982) }\end{array}$ & - & - & - \\
\hline $\mathrm{CO}_{3}^{2-}$ & $\begin{array}{l}\text {-527.81 (Wagman et al., } \\
\text { 1982) }\end{array}$ & $\begin{array}{l}-56.90 \text { (Wagman et al., } \\
1982 \text { ) }\end{array}$ & $\begin{array}{l}\text {-677.14 (Wagman } \\
\text { et al., 1982) }\end{array}$ & - & - & - \\
\hline $\mathrm{OH}^{-}$ & $\begin{array}{l}-157.24 \text { (Wagman et al., } \\
\text { 1982) }\end{array}$ & $\begin{array}{l}\text {-10.75 (Wagman et al., } \\
\text { 1982) }\end{array}$ & $\begin{array}{l}\text {-229.994 (Wagman } \\
\text { et al., 1982) }\end{array}$ & $\begin{array}{l}-148.50 \text { (Wagman } \\
\text { et al., } 1982 \text { ) }\end{array}$ & - & - \\
\hline
\end{tabular}

\subsubsection{Debye-Hückel theory}

Debye-Hückel theories assume the ions to be charged species with a fixed diameter in a continuous dielectric medium (Loehe and Donohue, 1997). The original Debye-Hückel formulation is valid only for very low concentrations, i.e., below $0.001 \mathrm{~m}$, due to assuming the ions to be point charges. The extended Debye-Hückel theory assigns a value to the ionic diameter and thus can be applied for concentrations up to $0.1 \mathrm{~m}$. The Debye-Hückel limiting law gives the activity coefficients $\gamma_{i}$ in terms of the ionic strength, $I$, which is defined by Eq. (22).

$I=\frac{1}{2} \sum_{i} m_{i} z_{i}^{2}$

where $z_{i}$ is the charge on ion $i$, and $m_{i}$ is the molality of ion $i$.

The activity coefficient can be calculated by the Debye-Hückel Limiting Law using Eq. (23)

$\log \gamma_{i}=-A \cdot z_{i}^{2} \cdot I^{1 / 2}$

where $A=0.509 /\left(\mathrm{mol} \mathrm{kg}^{-1}\right)^{1 / 2}$ for an aqueous solution at $25^{\circ} \mathrm{C}$. In general, $A$ depends on the relative permittivity of the solvent and the temperature.

The activity coefficient may be estimated from the extended Debye-Hückel law using Eq. (24).

$\log \gamma_{i}=\frac{-A \cdot z_{i}^{2} \cdot I^{1 / 2}}{1+b \cdot I^{1 / 2}}$

where $b$ is a measure of distance between ions. In the limit of small concentration $I^{1 / 2} \ll 1$, and, in the denominator of Eq. (24), $I^{1 / 2}$ can be neglected; the extended Debye-Hückel Law tends to become the Debye-Hückel Limiting Law at low concentrations, Eq. (23).

The Debye-Hückel and the extended Debye-Hückel theory are the basis of a number of successful semi-empirical equations for a variety of thermodynamic properties (Loehe and Donohue, 1997). Pitzer et al. established very widely applicable equations for high concentrations up to $6 \mathrm{~m}$, and discussed (Pitzer and Mayorga, 1973; Pitzer, 1991) the origin of these equations and their application in some detail (Loehe and Donohue, 1997). Below a brief description is presented of the Pitzer equations that have been used in this work.

\subsubsection{Pitzer model}

The Pitzer model can be considered as an extension of the Debye-Hückel model. The general formulation of the Pitzer model can be described by Eq. (25) which presents the total excess Gibbs energy. The first part of this equation corresponds to the Debye-Hückel model and is a function of ionic strength and the dielectric constant of the solvent (Hamrouni and Dhahbi, 2001). The second and the third terms are introduced to model the binary and ternary interactions which were neglected in the initial Debye-Hückel model. Pitzer introduced and formulated these two terms in order to describe the behavior of solutions at high concentrations (Hamrouni and Dhahbi, 2001).

$\frac{G^{e x}}{n_{w} R_{g} T}=f(I)+\sum_{i} \sum_{j} \lambda_{i j} m_{i} m_{j}+\sum_{i} \sum_{j} \sum_{k} \mu_{i j k} m_{i} m_{j} m_{k}$

where $f(I)$ is a function of ionic strength, expressing the effect of the long-range electrostatic forces; $i, j$ and $k$ are different anions (or cations), $m_{i}$ denotes molality of the $i$ th ion (moles per kilogram) and $n_{w}$ is number of kilograms of water. $\lambda_{i j}$ is a second virial coefficient which expresses the effect of the short-range forces between

Table 2

Calculated change in thermodynamic properties for reactions R1-R6 at $298.15 \mathrm{~K}$ and 1 bar.

\begin{tabular}{|c|c|c|c|c|c|c|}
\hline & $\Delta_{r} G^{o}(\mathrm{~kJ} / \mathrm{mol})$ & $\Delta_{r} S^{o}(\mathrm{~J} / \mathrm{mol} \mathrm{K})$ & $\Delta_{r} H^{o}(\mathrm{~kJ} / \mathrm{mol})$ & $\Delta_{r} C_{p}^{o}(\mathrm{~J} / \mathrm{mol} \mathrm{K})$ & $\Delta_{r} \overline{V^{0}}\left(\mathrm{~cm}^{3} / \mathrm{mol}\right)$ & $\overline{\Delta_{r} \overline{K^{0}}}\left(\mathrm{~cm}^{3} / \mathrm{MPa} \mathrm{mol}\right)$ \\
\hline $\mathrm{R} 1$ & 79.890 & -80.66 & 55.836 & -223.79 & -18.068 & - \\
\hline $\mathrm{R} 2$ & 40.07 & -58.2 & 22.100 & -270.50 & -19.120 & - \\
\hline R3 & 96.591 & -77.4 & 50.700 & -53.600 & 8.0600 & - \\
\hline $\mathrm{R} 4$ & 44.730 & -96.31 & -12.6500 & - & - & - \\
\hline R5 & 192.40 & 26.4 & 14.8500 & - & - & - \\
\hline R6 & 48.805 & - & 132.22 & 182.10 & -13.820 & 0.00007 \\
\hline
\end{tabular}


species $i$ and $j . \lambda_{i j}$ is dependent on the ionic strength. $\mu_{i j k}$ is the third virial coefficient which accounts for triple ion interactions; $\mu_{i j k}$ is independent of the ionic strength (Pitzer and Kim, 1974).

The activity coefficient equations are obtained by appropriate derivations from Eq. (25) which are described in detail in Pitzer and Mayorga (1973), Pitzer (1975, 1991) and Pitzer and Kim (1974). Eqs. (26) and (27) are used to obtain the ionic activity coefficients for cations $M$ and anions $X$ :

$$
\begin{aligned}
\ln \left(\gamma_{M}\right)= & z_{M}^{2} F+\sum_{a} m_{a}\left(2 B_{M a}+Z C_{M a}\right) \\
& +\sum_{c} m_{c}\left(2 \Phi_{M c}+\sum_{a} m_{a} \psi_{M c a}\right) \\
& +\sum_{a<} \sum_{a^{\prime}} m_{a} m_{a^{\prime}} \psi_{a a^{\prime} M}+z_{M} \sum_{c} \sum_{a} m_{c} m_{a} C_{c a} \\
\ln \left(\gamma_{X}\right)= & z_{X}^{2} F+\sum_{c} m_{c}\left(2 B_{c X}+Z C_{c X}\right) \\
& +\sum_{a} m_{a}\left(2 \Phi_{X a}+\sum_{c} m_{c} \psi_{X a c}\right) \\
& +\sum_{c<} \sum_{c^{\prime}} m_{c} m_{C^{\prime}} \psi_{c c^{\prime} X}+\left|z_{X}\right| \sum_{c} \sum_{a} m_{c} m_{a} C_{c a}
\end{aligned}
$$

The osmotic coefficient $\phi_{\text {osmotic }}$ which characterizes the deviation of solvent from ideal behavior can be calculated using Eq. (28).

$$
\begin{aligned}
\left(\phi_{\text {osmotic }}-1\right)=\frac{2}{\sum_{i} m_{i}}[ & \frac{-A_{\varphi} I^{3 / 2}}{\left(1+b I^{1 / 2}\right)}+\sum_{c} \sum_{a} m_{c} m_{a}\left(B_{c a}^{\varphi}+Z C_{c a}\right) \\
& +\sum_{c<} \sum_{c^{\prime}} m_{c} m_{c^{\prime}}\left(\Phi_{c c^{\prime}}^{\varphi}+\sum_{a} m_{a} \psi_{c c^{\prime} a}\right) \\
& \left.+\sum_{a<} \sum_{a^{\prime}} m_{a} m_{a^{\prime}}\left(\Phi_{a a^{\prime}}^{\varphi}+\sum_{c} m_{c} \psi_{c a a^{\prime}}\right)\right]
\end{aligned}
$$

The various terms in Eqs. (26)-(28) are defined as follows:

$I$ is the ionic strength which is defined by Eq. (22).

The term $F$ in Eqs. (26) and (27) is defined by Eq. (29)

$$
\begin{aligned}
F= & f^{\gamma}+\sum_{c} \sum_{a} m_{c} m_{a} B_{c a}^{\prime}+\sum_{c<} \sum_{c^{\prime}} m_{c} m_{c^{\prime}} \Phi_{c c^{\prime}}^{\prime} \\
& +\sum_{a<} \sum_{a^{\prime}} m_{a} m_{a^{\prime}} \Phi_{a a^{\prime}}^{\prime}
\end{aligned}
$$

where $f^{\gamma}$ is defined by Eq. (30)

$f^{\gamma}=-A_{\varphi}\left[\frac{I^{1 / 2}}{1+b I^{1 / 2}}+\frac{2}{b} \ln \left(1+b I^{1 / 2}\right)\right]$

where $b$ is 1.2 and $A_{\varphi}$, which is the Debye-Hückel slope. The variation of the Debye-Hückel slope, $A_{\varphi}$, for the activity coefficient with temperature can be expressed by Eq. (31) (Møller, 1988).

$$
\begin{aligned}
A_{\varphi}= & 3.6901531 \times 10^{-1}-6.32100430 \times 10^{-4} T+\frac{9.1425359}{T} \\
& -1.35143986 \times 10^{-2} \ln T+\frac{2.26089788 \times 10^{-3}}{T-263} \\
& +1.92118597 \times 10^{-6} T^{2}+\frac{4.52586464 \times 10^{1}}{680-T}
\end{aligned}
$$

where $T$ is the absolute temperature in Kelvin.
The variables $B_{M X}, B_{M X}^{\varphi}$ and $C_{M X}$ which define the thermodynamic properties of single-salts solution are given below by

$B_{M X}=\beta_{M X}^{(0)}+\beta_{M X}^{(1)} g\left(\alpha_{1} I^{1 / 2}\right)+\beta_{M X}^{(2)} g\left(\alpha_{2} I^{1 / 2}\right)$

in which:

$$
\begin{aligned}
& g(x)=2\left[1-(1-x) e^{-x}\right] / x^{2} \\
& g^{\prime}(x)=-2\left[1-\left(1+x+0.5 x^{2}\right) e^{-x}\right] / x^{2} \\
& B^{\prime}(x)=\beta_{M X}^{(1)} g^{\prime}\left(\alpha_{1} I^{1 / 2}\right) / I+\beta_{M X}^{(2)} g^{\prime}\left(\alpha_{2} I^{1 / 2}\right) / I \\
& B_{M X}^{\varphi}=\beta_{M X}^{(0)}+\beta_{M X}^{(1)} \exp \left(-\alpha_{1} I^{1 / 2}\right)+\beta_{M X}^{(2)} \exp \left(-\alpha_{2} I^{1 / 2}\right) \\
& C_{M X}=\frac{C^{\varphi}}{2\left|z_{M} z_{X}\right|^{1 / 2}}
\end{aligned}
$$

The parameters $\beta^{(0)}, \beta^{(1)}, \beta^{(2)}$, and $C^{\varphi}$, which define the variables $B$ and $C$, are fitted from single-salt data (Plummer et al., 1988) and the literature values of these parameters are tabulated in Kuranov et al. (1996) and Kamps et al. (2000). For any salt containing a monovalent ion such as 1-1 (e.g. $\mathrm{NaCl}$ ), 1 -2 (e.g. $\mathrm{Na}_{2} \mathrm{SO}_{4}$ ) or 2-1 (e.g. $\left.\mathrm{CaCl}_{2}\right) \alpha_{1}=2$ and $\alpha_{2}=0$. For 2-2 (e.g. CaSO 4 ) electrolytes $\alpha_{1}=1.4$ and $\alpha_{2}=12.0$. For 3-2 and 4-2 electrolytes $\alpha_{1}=2$ and $\alpha_{2}=50$ (Pitzer and Silvester, 1978).

The coefficient to $C_{M x}, Z$, in Eqs. (26)-(28) is defined by Eq. (38) below:

$Z=\sum_{i} m_{i}\left|z_{i}\right|$

The parameters $\Phi$ and $\psi$ are determined from two-salt systems. $\Phi$ accounts for cation-cation and anion-anion interactions while the parameter $\psi$ is defined for cation-cation-anion and anion-anion-cation interactions. Values of $\Phi_{i j}$ can be determined using Eqs. (39)-(46)

$$
\begin{aligned}
& \Phi_{i j}^{\varphi}=\theta_{i j}+I^{E} \theta_{i j}^{\prime}(I)+{ }^{E} \theta_{i j}(I) \\
& \Phi_{i j}=\theta_{i j}+{ }^{E} \theta_{i j}(I) \\
& \Phi_{i j}^{\prime}={ }^{E} \theta_{i j}^{\prime}(I) \\
& { }^{E} \theta_{i j}(I)=\left(\frac{\left|z_{i} z_{j}\right|}{4 I}\right)\left[J\left(x_{i j}\right)-0.5 J\left(x_{i i}\right)-0.5 J\left(x_{j j}\right)\right] \\
& { }^{E} \theta_{i j}^{\prime}=\left(\frac{{ }^{E} \theta_{i j}}{I}\right)+\left(\frac{\left|z_{i} z_{j j}\right|}{8 I^{2}}\right) \cdot\left[x_{i j} J^{\prime \prime}\left(x_{i j}\right)-0.5 x_{i i} J^{\prime \prime}\left(x_{i i}\right)-0.5 x_{j j} J^{\prime \prime}\left(x_{j j}\right)\right]
\end{aligned}
$$

$x_{i j}=6\left|z_{i} z_{j}\right| A_{\varphi} I^{0.5}$

$J(x)=x\left[4+4.581 x^{-0.7237} \exp \left(-0.0120 x^{0.528}\right)\right]^{-1}$ 
$J^{\prime \prime}(x)=\frac{4+\left[4.581 x^{-0.7237} \exp \left(-0.0120 x^{0.528}\right)\right]\left[0.006336 x^{0.528}+1.7237\right]}{\left[4+4.581 x^{-0.7237} \exp \left(-0.012 x^{0.528}\right)\right]^{2}}$

In the above equations $m_{i}$ denotes molality of the $i$ th ion (moles per kilogram) where the subscripts $M, c$ and $c^{\prime}$ refer to cations and the subscripts $X, a$ and $a^{\prime}$ to anions. The summation index, $c$, denotes the sum over all cations in the system while the double summation index, $c<c^{\prime}$, denotes the sum over all distinguishable pairs of dissimilar cations. Similar definitions apply to the summation indices for anions $X, a$ and $a^{\prime}$. $B$ and $f$ represent measurable combinations of the second virial coefficients $\lambda$. $C$ and $\psi$ represent measurable combinations of the third virial coefficients $\mu$ (Hamrouni and Dhahbi, 2001). The terms ${ }^{E} \theta_{i j}$ and ${ }^{E} \theta_{i j}^{\prime}$ account for electrostatic mixing effects of unsymmetrical cation-cation and anion-anion pairs (Pitzer, 1975). Values of ${ }^{E} \theta_{i j}$ and ${ }^{E} \theta_{i j}^{\prime}$ depend only on ion charge and total ionic strength and are zero when $i j$ cation or anion pairs have the same charge (Plummer et al., 1988).

Pitzer ion interaction parameters $\beta^{(0)}, \beta^{(1)}, \beta^{(2)}, \theta, \psi$ and $C^{\varphi}$ are functions of temperature. The values of the binary interaction parameters as function of temperature are given in Kuranov et al. (1996) and Kamps et al. (2000).

Three separate Matlab programs have been written for calculating the anion and cation activity coefficients and the osmotic coefficient in the aqueous amine stream using Eqs. (22)-(46). These programs can be used to calculate the activity coefficient and osmotic pressure for any solution with known initial composition.

\section{Results and discussion}

The objective of this work is to predict the solubility of acid gases using an improved thermodynamic model. The model is based on a set of equations for chemical equilibria, phase equilibria, charge, and mass balances. Non-ideality in the liquid and gas phases was taken into account by using the Pitzer model to calculate the activity coefficients and using the PR equation of state to calculate the fugacity coefficients.

\subsection{Model validation}

To assess the validity of the model for $\mathrm{CO}_{2}$ and $\mathrm{H}_{2} \mathrm{~S}$ solubilities prediction, a comparison was made with the available data reported by Lemoine et al. (2000) and Huttenhuis et al. (2007) as

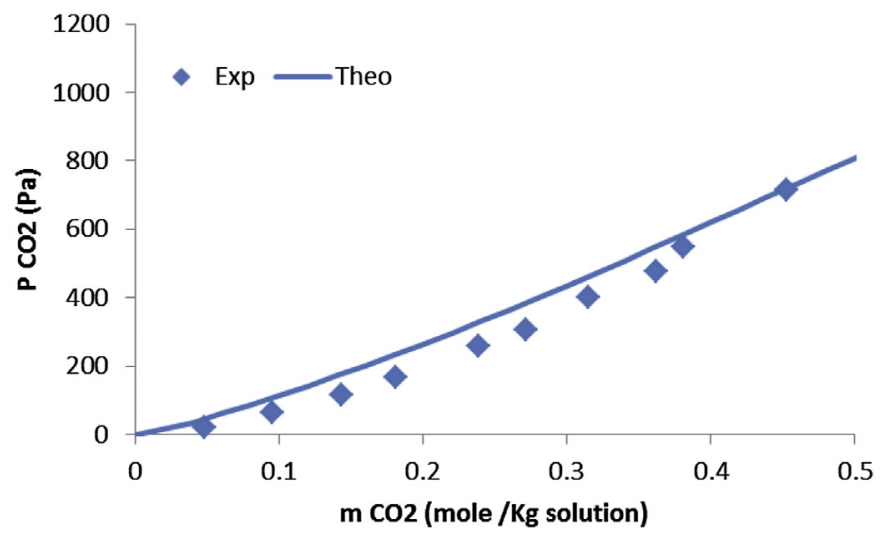

Fig. 1. Comparison between predicted $P_{\mathrm{CO}_{2}}$ and the data of the data of Lemoine et al. (2000) at $298 \mathrm{~K}$ and $23.63 \mathrm{wt}$. \% of MDEA $\left(R^{2}=0.985\right)$. shown in Figs. 1 and 2 and Fig. 3, respectively. In Fig. 1 the data of Lemoine et al. were obtained for $\mathrm{CO}_{2}$ solubilities in $23.63 \mathrm{wt} . \%$ MDEA aqueous solutions at $298 \mathrm{~K}$, and in Fig. 2 the data were obtained for $\mathrm{H}_{2} \mathrm{~S}$ solubilities at temperatures of $313.15 \mathrm{~K}$ in 2.5 (mol/ $\mathrm{kg} \mathrm{H}_{2} \mathrm{O}$ ) MDEA solution. The data of Huttenhuis et al. were obtained for $\mathrm{H}_{2} \mathrm{~S}$ solubilities at $298.15 \mathrm{~K}$ in an $8.39 \mathrm{~m}$ MDEA solution. An overall good agreement between experimental and predicted values was obtained. The deviations between the experimental and predicted data can be due to systematic experimental errors as explained in Lemoine et al. (2000). It should be noted that rigor of the simulation is of secondary importance in the current paper as the novelty of the paper and hence "primary" importance is to introduce our fundamental and realistic approach of using new theoretical thermodynamic model based on incorporating theoretical thermodynamic relationships that correlates the equilibrium and solubility constants to the Gibbs free energy of reactions and using of Pitzer model.

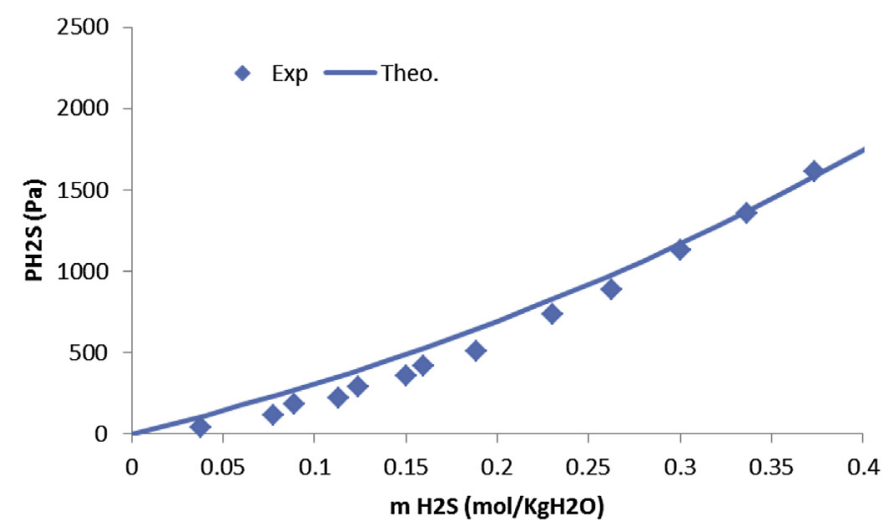

Fig. 2. Comparison between predicted $P_{\mathrm{H}_{2} \mathrm{~S}}$ and the data of Lemoine et al. (2000) at $313.15 \mathrm{~K}$ and $2.5 \mathrm{~m}$ of MDEA $\left(R^{2}=0.9986\right)$.

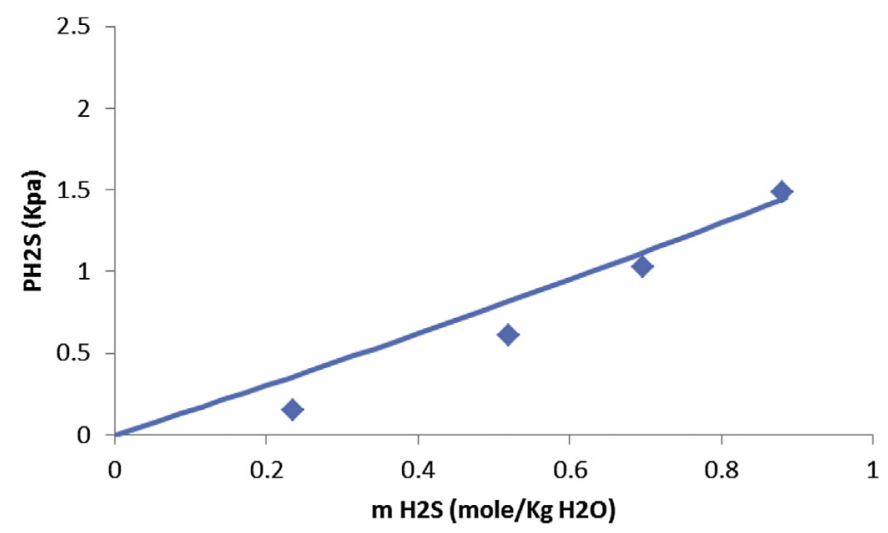

Fig. 3. Comparison between predicted $P_{\mathrm{H}_{2} \mathrm{~S}}$ and the data of Huttenhuis et al. (2007) at $298.15 \mathrm{~K}$ and $8.39 \mathrm{~m}$ of MDEA $\left(R^{2}=0.989\right)$. 


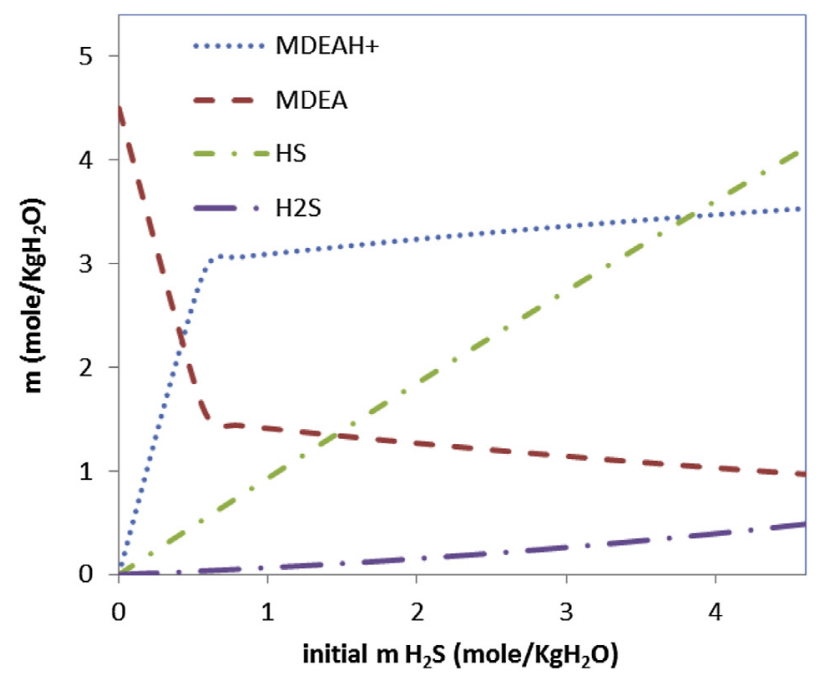

Fig. 4. Species concentration profile for aqueous solution of $\left[\mathrm{H}_{2} \mathrm{~S}+\mathrm{MDEA}+\mathrm{H}_{2} \mathrm{O}\right]$ at $313.15 \mathrm{~K}\left(\bar{m}_{\mathrm{MDEA}}=4.5 \mathrm{~mol}(\mathrm{~kg} \text { water })^{-1}\right)$.

\subsection{Speciation prediction}

The concentrations of the different species in the $\mathrm{H}_{2} \mathrm{~S}$ and aqueous MDEA system were evaluated using the model. Fig. 4 gives the predicted speciation of $\left(\mathrm{MDEA}^{+}, \mathrm{H}_{2} \mathrm{O}\right.$, and $\left.\mathrm{H}_{2} \mathrm{~S}\right)$ solution at $\bar{m}_{\text {MDEA }}=4.5 \mathrm{~mol}(\mathrm{~kg} \text { water })^{-1}$ and $313.15 \mathrm{~K}$.

It was found that at the simulated conditions most of the $\mathrm{H}_{2} \mathrm{~S}$ absorbed into the solution is in the form of $\mathrm{HS}^{-}$with a small amount in the form of $\mathrm{H}_{2} \mathrm{~S}$. As the loading increase, the concentration of $\mathrm{MDEA}^{+}$increases and the concentration of MDEA decreases. However, the will change in the MDEA and MDEA ${ }^{+}$ concentrations will be limited once the entail $\mathrm{H}_{2} \mathrm{~S}$ concentration exceeds $6 \mathrm{~m}$.

\subsection{Effect of process temperature}

The effect of temperature on the solubility of acid gases has been examined as well. As can be seen in Fig. 5, increasing system temperature up to $383.15 \mathrm{~K}$ decreases the solubility of acid gases. However, further increase of the system temperature above $383.15 \mathrm{~K}$ decreases the partial pressure of $\mathrm{H}_{2} \mathrm{~S}$. Increasing the temperature has affected the reaction equilibrium as can be seen in Fig. 6.

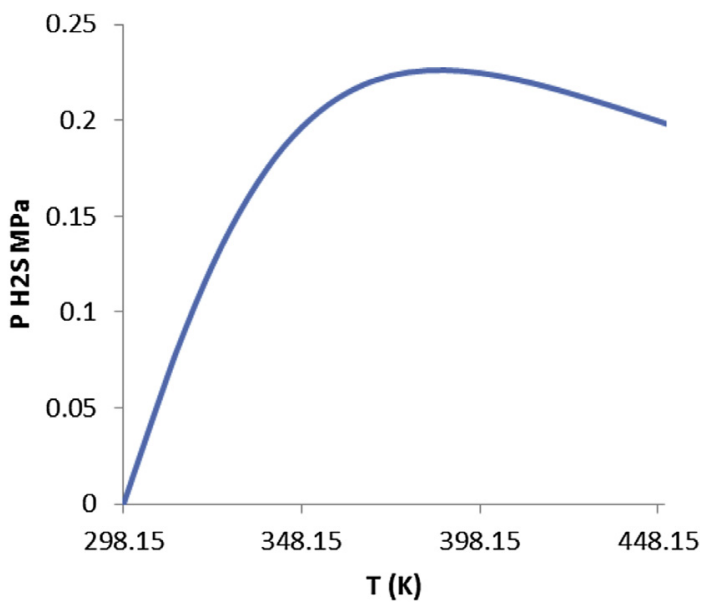

Fig. 5. Effect of temperature change on $\mathrm{H}_{2} \mathrm{~S}$ partial pressure in initial $8.39 \mathrm{~m}$ MDEA and various $\mathrm{H}_{2} \mathrm{~S}$ loadings from 0 to $3.1 \mathrm{~m}$.

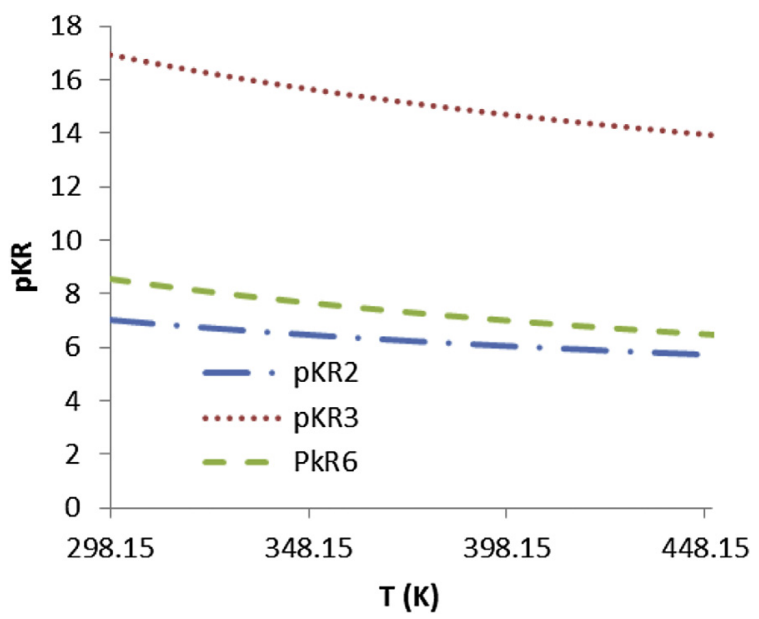

Fig. 6. Equilibrium constant for R2, R3 and R6 versus temperature.

Fig. 7 shows the effect of temperature change on the concentrations of $\mathrm{MDEA}^{+}$and MDEA at an initial MDEA concentration of $8.39 \mathrm{~m}$. As can be seen from Fig. 7, as the temperature of the system increases, the concentration of MDEA ${ }^{+}$in the system decreases and the concentration of MDEA increases. This decrease of MDEA ${ }^{+}$ decreases the solubility of $\mathrm{H}_{2} \mathrm{~S}$, and contributes to increase the partial pressure of $\mathrm{H}_{2} \mathrm{~S}$ as a consequence of the temperature increase.

\subsection{Effect of solution $\mathrm{pH}$}

Fig. 8 shows the effect of the $\mathrm{pH}$ of the solution on the solubility of $\mathrm{H}_{2} \mathrm{~S}$. As can be seen from Fig. 8, increasing of the system $\mathrm{pH}$ increases the solubility of $\mathrm{H}_{2} \mathrm{~S}$ in the amine solution. Increasing the $\mathrm{pH}$ of the solution shifts the reaction to dissolved more $\mathrm{H}_{2} \mathrm{~S}$ and produced more $\mathrm{HS}^{-}$and $\mathrm{S}^{2-}$.

\subsection{Effect of process pressure on solubility}

Also the effect of the process pressure has been studied. As can be seen in Fig. 9, increasing of the process pressure increases the

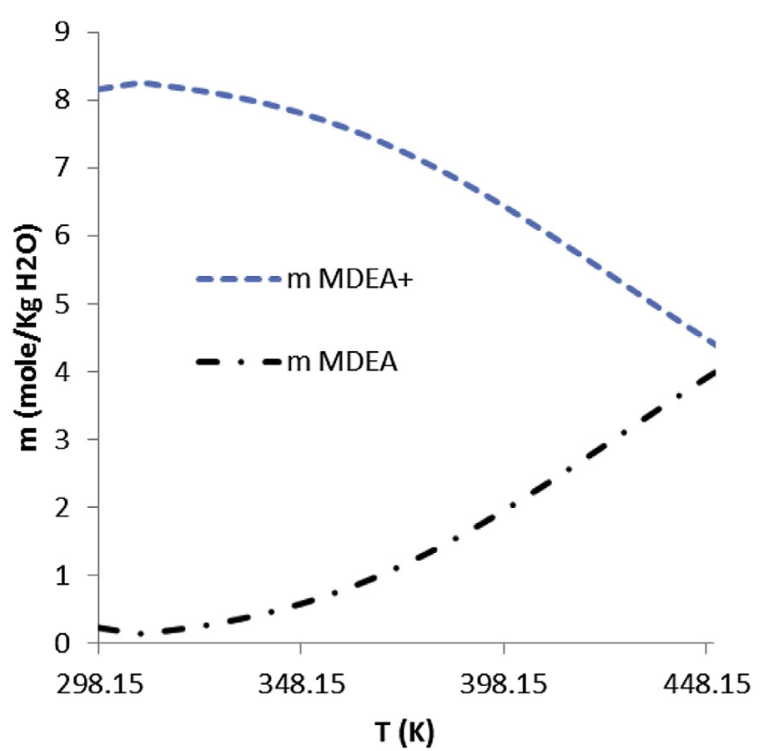

Fig. 7. Effect of temperature change on the concentration of MDEA+ and MDEA at initial $8.39 \mathrm{~m}$ MDEA 


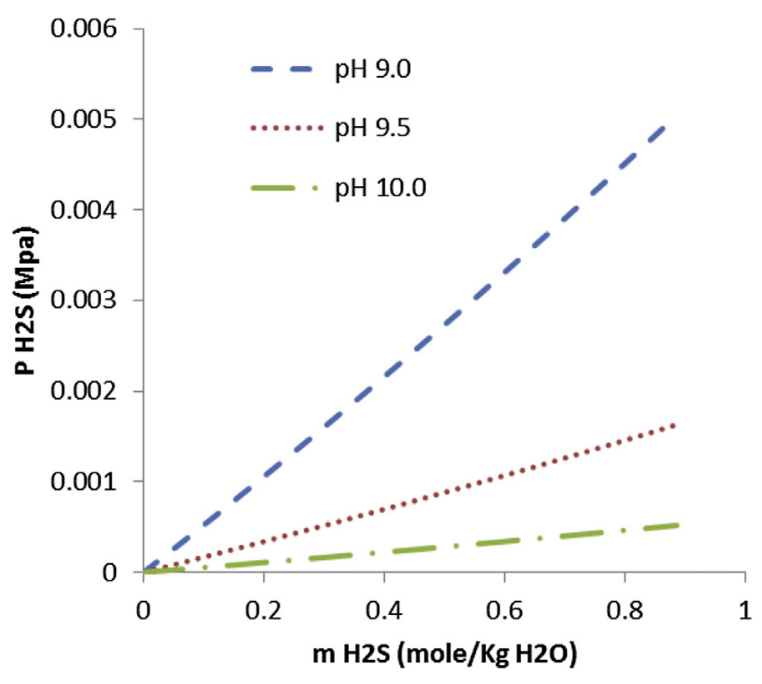

Fig. 8. Effect of solution $\mathrm{pH}$ on $\mathrm{H}_{2} \mathrm{~S}$ solubility in $8.39 \mathrm{~m}$ MDEA solution.

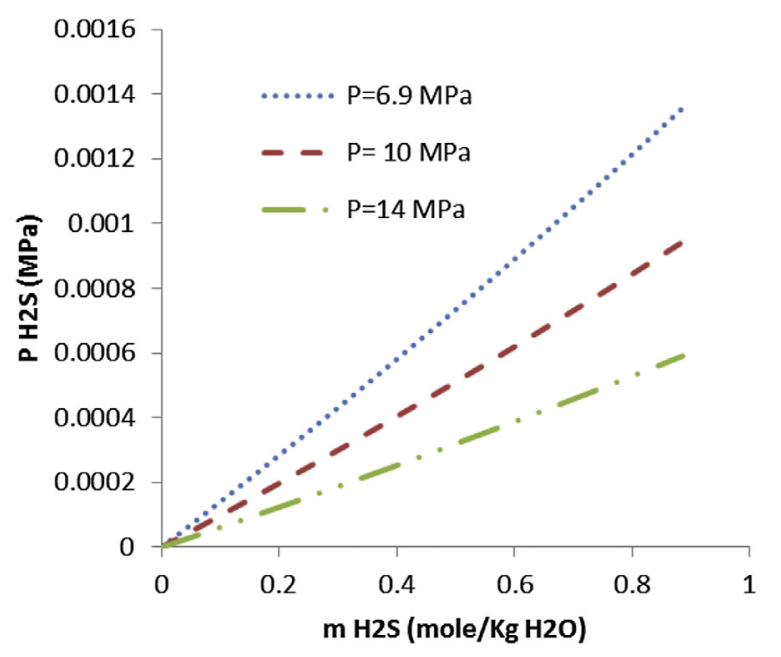

Fig. 9. Effect of process pressure on $\mathrm{H}_{2} \mathrm{~S}$ solubility in $8.39 \mathrm{~m}$ MDEA solution.

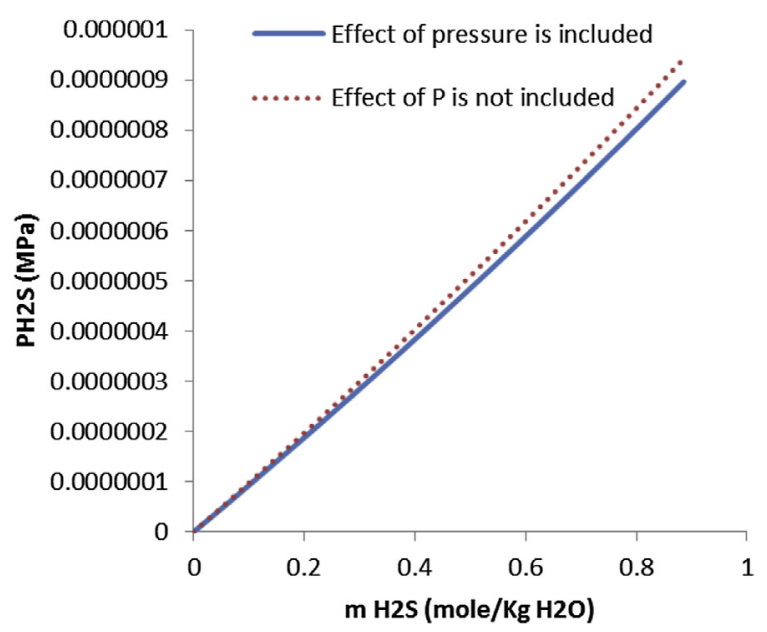

Fig. 10. The effect of including process pressure (69 MPa) in the thermodynamic equilibrium constants' calculation at $\mathrm{H}_{2} \mathrm{~S}$ solubility at constant temperature $25^{\circ} \mathrm{C}$ and initial 8.39 m MDEA. solubility of $\mathrm{H}_{2} \mathrm{~S}$. The effect of the process pressure on the thermodynamic equilibrium constant has been included and evaluated in Fig. 10. Interestingly, the effect of process pressure increased as the initial concentration of $\mathrm{H}_{2} \mathrm{~S}$ increased, which indicates that at high $\mathrm{H}_{2} \mathrm{~S}$ loading the effect of process pressure on the equilibrium constants should not be ignored.

\section{Conclusions}

In this paper, a new thermodynamic model was proposed to predict the solubility of acid gases in the amine absorption processes. The fundamental equations of Gibbs free energy of reaction have been used to calculate the thermodynamic equilibrium constants of all reactions involved in the acid gas absorption system. The effect of process pressure and temperature was incorporated theoretically in this model. The non-ideality in the liquid phase was taken into account by using the Pitzer model to calculate the activity coefficients for all species present in the liquid phase. The non-ideality in the gas phase was taken into account by using the PR equation of state to calculate the fugacity coefficient for all species present in the gas phase.

The model has been positively validated through comparison with experimental data. The effects of process temperature, pressure, and $\mathrm{pH}$ on the $\mathrm{H}_{2} \mathrm{~S}$ solubility in MDEA amine solutions were evaluated. This model forms the basis for an adequate assessment of the effect of the presence of multiple dissolved species that also may occur in real amine absorption processes. Also this model could be further developed to a user-friendly program, able to give an accurate prediction of acid gas solubilities at actual process conditions, allowing the optimization of the process accordingly.

\section{Acknowledgments}

The authors are grateful to the Gas Research Centre at The Petroleum Institute in Abu Dhabi for funding the project (GRC006).

\section{Nomenclature}

$A_{\varphi} \quad$ interaction parameter Pitzer model (-)

$B, B^{\prime}, B^{\varphi}$ interaction parameter Pitzer model (-)

$C, C^{\varphi} \quad$ interaction parameter Pitzer model (-)

$f^{\varphi} \quad$ interaction parameter Pitzer model (-)

G $\quad$ standard Gibbs free energy

I ionic strength, $\mathrm{mol} / \mathrm{kg}$

$K_{\mathrm{R}} \quad$ thermodynamic solubility product

$P \quad$ process pressure, bar

$P_{0} \quad$ reference pressure, 1 bar

$R_{g} \quad$ the universal gas constant

$T \quad$ temperature, $\mathrm{K}$

$V \quad$ volume of the dissolution reaction

$\bar{V} \quad$ molal volume of dissolution reaction

$z_{i} \quad$ ionic charge of component $i$

$Z \quad$ modified ionic strength, $\mathrm{mol} / \mathrm{kg}$

\section{Greek letter}

$\alpha_{1}, \alpha_{2} \quad$ interaction parameter Pitzer model (-)

$\Delta \quad$ denote the difference between two values

$\Delta_{r} C_{p}^{o} \quad$ standard heat capacity change of reaction

$\Delta_{f} G^{\varphi} \quad$ standard Gibbs free energy change of formation

$\Delta_{\text {reac }} G^{\varphi}$ standard molar Gibbs free energy change of reaction

$\Delta H_{\text {reac }}$ enthalpy change of reaction

$\Delta_{r} H^{O} \quad$ standard enthalpy change of reaction

$\Delta K_{r}^{0} \quad$ standard compressibility change of reaction

$\Delta \overline{K_{r}^{0}} \quad$ standard molal compressibility change of reaction

$\Delta_{r} S^{o} \quad$ standard entropy change of reaction 


$\begin{array}{ll}\Delta V_{r}^{0} & \text { standard volume change of reaction } \\ \Delta \overline{V_{r}^{0}} & \text { standard molal volume change of reaction } \\ \gamma & \text { activity coefficient } \\ \Phi, \Phi^{\prime}, \Phi^{\varphi} & \text { Interaction parameter Pitzer model }(-) \\ \phi_{\text {osmotic }} & \text { Pitzer osmotic coefficient } \\ \lambda_{i j} & \text { the second virial coefficient } \\ \mu_{i j k} & \text { third virial coefficient } \\ \Psi & \text { interaction parameter Pitzer model }(-)\end{array}$

\section{References}

Alhseinat, E., Sheikholeslami, R., 2012. A completely theoretical approach for assessing fouling propensity along a full-scale reverse osmosis process. Desalination 301, 1-9.

Anderko, A., Wang, P., Rafal, M., 2002. Electrolyte solutions: from thermodynamic and transport property models to the simulation of industrial processes. Fluid Phase Equilib. 194-197, 123-142.

Barbero, J.A., McCurdy, K.G., Tremaine, P.R., 1982. Apparent molal heat capacities and volumes of aqueous hydrogen sulphide and sodium hydrogen sulfide near $25{ }^{\circ} \mathrm{C}$ : the temperature dependence of $\mathrm{H}_{2} \mathrm{~S}$ ionization. Can. J. Chem. 60, 1872-1880.

Benamor, A., Aroussi, A., 2013. Modeling analysis of $\mathrm{CO}_{2}$ solubility in solutions of DEA, MDEA and their mixtures using Kent-Eisenberg and Deshmukh-Mather models. In: 3rd International Conference on Chemical, Biological and Environment Sciences (ICCEBS'2013), pp. 80-85. Kuala Lumpur, Malaysia.

Chen, C.C., Evans, L.B.A., 1986. Local composition model for the excess Gibbs energy of aqueous electrolyte system. AIChE J. 32.

Deshmukh, R.D., Mather, A.E., 1981. A mathematical model for equilibrium solubility of hydrogen sulfide and carbon dioxide in aqueous alkanolamine solutions. Chem. Eng. Sci. 36.

George Hayden, J., O'Connell, J.P., 1975. A generalized method for predicting second virial coefficients. Chem. Process Des. Dev. 14 (3).

Hamrouni, B., Dhahbi, M., 2001. Thermodynamic description of saline waters prediction of scaling limits in desalination processes. Desalination 137 (1-3), $275-284$.

Huttenhuis, P.J.G., et al., 2007. Gas solubility of $\mathrm{H}_{2} \mathrm{~S}$ and $\mathrm{CO}_{2}$ in aqueous solutions of N-methyldiethanolamine. J. Pet. Sci. Eng. 55 (1-2), 122-134.

Kamps, Á.P.-S., et al., 2000. Solubility of single gases carbon dioxide and hydrogen sulfide in aqueous solutions of $\mathrm{N}$-methyldiethanolamine at temperatures from 313 to $393 \mathrm{~K}$ and pressures up to $7.6 \mathrm{MPa}$ : new experimental data and model extension. Ind. Eng. Chem. Res. 40 (2), 696-706.

Kent, R.L., Eisenberg, B., 1976. Better data for amine treating. Hydrocarb. Process. 55 (2).

Kuranov, G., et al., Jun 1996. Solubility of single gases carbon dioxide and hydrogen sulfide in aqueous solutions of $\mathrm{N}$-methyldiethanolamine in the temperature range $313-413 \mathrm{~K}$ at pressures up to $5 \mathrm{MPa}$. Ind. Eng. Chem. Res. 35 (6), 1959-1966.

Lemoine, $\mathrm{B}$. et al., 2000. Partial vapor pressure of $\mathrm{CO}_{2}$ and $\mathrm{H}_{2} \mathrm{~S}$ over aqueous methyldiethanolamine solutions. Fluid Phase Equilib. 172 (2), 261-277.
Loehe, J.R., Donohue, M.D., 1997. Recent advances in modeling thermodynamic properties of aqueous strong electrolyte systems. AIChE J. 43 (1), 180-195.

Møller, N., 1988. The prediction of mineral solubilities in natural waters: a chemical equilibrium model for the $\mathrm{Na}-\mathrm{Ca}-\mathrm{Cl}-\mathrm{SO}_{4}-\mathrm{H}_{2} \mathrm{O}$ system, to high temperature and concentration. Geochim. Cosmochim. Acta 52 (4), 821-837.

Monnin, C., 1999. A thermodynamic model for the solubility of barite and celestite in electrolyte solutions and seawater to $200{ }^{\circ} \mathrm{C}$ and to $1 \mathrm{kbar}$. Chem. Geol. 153 (1-4), 187-209.

Peng, D.Y., Robinson, D.B., 1976. A new two constant equation of state. Ind. Eng. Chem. Fundam. 15 (1), 59.

Pitzer, K.S., 1975. Thermodynamics of electrolytes. V. Effects of higher-order electrostatic terms. J. Solut. Chem. 4 (3), 249-265.

Pitzer, K.S., Kim, J.J., 1974. Thermodynamics of electrolytes. IV. Activity and osmotic coefficients for mixed electrolytes. J. Am. Chem. Soc. 96 (18), 5701-5707.

Pitzer, K.S., Mayorga, G., 1973. Thermodynamics of electrolytes. II. Activity and osmotic coefficients for strong electrolytes with one or both ions univalent. J. Phys. Chem. 77 (19), 2300-2308.

Pitzer, K.S., Silvester, L.F., 1978. Thermodynamics of electrolytes. 11. Properties of 3: 2, 4:2, and other high-valence types. J. Phys. Chem. 82 (11), 1239-1245.

Pitzer, K.S., 1991. Activity Coefficients in Electrolyte Solutions, second ed. C. Press, Boston.

Plummer, L.N., et al., 1988. A Computer Program Incorporating Pitzer's Equations for Calculation of Geochemical Reactions in Brines. Water-Resources Investigations Report.

Rushdi, A.I., McManus, J., Collier, R.W., 2000. Marine barite and celestite saturation in seawater. Mar. Chem. 69 (1-2), 19-31.

Sheikholeslami, R., 2004. Assessment of the scaling potential for sparingly soluble salts in RO and NF units. Desalination 167, 247-256.

Sheikholeslami, R., 2005. Scaling potential index (SPI) for $\mathrm{CaCO}_{3}$ based on Gibbs free energies. AIChE J. 51 (6), 1782-1789.

Soave, G., 1972. Equilibrium constants from a modified Redlich-Kwong equation of state. Chem. Eng. Sci. 27, 1197.

Speyer, D., Ermatchkov, V., Maurer, G., 2009. Solubility of carbon dioxide in aqueous solutions of $\mathrm{N}$-methyldiethanolamine and piperazine in the low gas loading region. J. Chem. Eng. Data 55 (1), 283-290.

Speyer, D., Böttger, A., Maurer, G., 2012. Solubility of hydrogen sulfide in aqueous solutions of $\mathrm{N}$-methyldiethanolamine and piperazine. Ind. Eng. Chem. Res. 51 (38), 12549-12556.

van der Stegen, J.H.G., et al., 1999. Application of the Pitzer model for the estimation of activity coefficients of electrolytes in ion selective membranes. Fluid Phase Equilib. 157 (2), 181-196.

Wagman, D.D., et al., 1982. The NBS tables of chemical thermodynamic properties selected values for inorganic and C1 and C2 organic substances in SI units. J. Phys. Chem. Ref. Data 11 (2).

Zhang, Y., Chen, C.-C., 2010. Thermodynamic modeling for $\mathrm{CO}_{2}$ absorption in aqueous MDEA solution with electrolyte NRTL model. Ind. Eng. Chem. Res. 50 (1), 163-175.

Zhang, K., et al., 2002. Thermodynamics of aqueous amines: excess molar heat capacities, volumes, and expansibilities of \{water + methyldiethanolamine (MDEA) $\}$ and $\{$ water +2 -amino-2-methyl-1-propanol (AMP) $\}$. J. Chem. Thermodyn. 34 (5), 679-710. 